\title{
Jaime Court Lobo: El retiro de un Maestro
}

\author{
M arco Antonio Soza M . ${ }^{1}$
}

El Dr. Jaime Court Lobo, Profesor Titular de N eurología de la Pontificia Universidad Católica de Chile y docente de su Facultad de Medicina desde 1968, se ha acogido a retiro a partir de Diciembre de 2004.

M ás de 60 los neurólogos chilenos y extranjeros deben a él su especialización. Por formar escuela, la Sociedad de Neurología, Psiquiatría y Neurocirugía le confirió en 1994, el reconocimiento de $M$ aestro de la N eurología de Chile.

Jaime Court nació en Santiago de Chile el 27 de Noviembre de 1936. Sus padres fueron Don Alfonso Court Artigas y Doña Olga Lobo Parga, de cuyo matrimonio nacieron 6 hijos. Doña Olga fallece a los 39 años de edad de un cáncer mamario, dejando al menor Rodrigo con tan sólo 4 meses de vida. Esta tragedia impactó profundamente a Jaime quien en ese entonces contaba sólo con 16 años de edad. Con frecuencia se refiere a su madre con profundo afecto y nostalgia y recuerda como ella le daba sus primeras lecciones de piano. Fue también su madre quien le manifestó más de una vez su anhelo de que estudiara medicina. Su tío materno, el eximio pediatra Dr. Gabriel Lobo Parga ya figura en los anales de la medicina chilena como uno de quienes más ha contribuido al desarrollo de su especialidad. Sin duda su ejemplo fue también un estímulo para que Court eligiera la profesión de médico.

Jaime Court estudió en el Colegio Saint George de Santiago y contrajo matrimonio con Doña Ingrid Viviani Richard, de profesión enfermera universitaria y socióloga, con quien tiene sus tres hijos. De ellos han nacido sus 9 nietos que junto al resto de su familia, le han dado las mayores alegrías que la vida puede otorgar.

En su vida universitaria, Court fue un activo militante de la Acción Católica, agrupación que llegó a presidir y en cuya representación viajó a varios países incluyendo la Ciudad del Vaticano. Fue miembro de Pax Romana, institución que desde su fundación en Roma en 1947, agrupa a profesionales e intelectuales católicos con el objeto de promover el diálogo entre diferentes culturas, profesiones y generaciones para favorecer la paz y la solidaridad entre los pueblos. Dentro de las aficiones de Jaime Court figuran el deporte del fútbol y coleccionar bastones antiguos, pipas y cajas de madera. Goza con la observación de la naturaleza, la música selecta y la lectura de los clásicos literarios, particularmente de la Biblia y Don Quijote de la M ancha. En la actualidad, ya retirado de las actividades académicas y asistenciales, continúa leyendo y estudiando los textos de Neurología.

Recibido: 28 Julio 2005

Aceptado: 16 Diciembre 2005

1 Departamento de Neurología, Pontificia Universidad Católica de Chile. 
Jaime Court fue un alumno destacado en la Facultad de Medicina de la Pontificia Universidad Católica de Chile, obteniendo el título Médico Cirujano en 1962. Entre los años 1963 y 1965 cursó una beca de Neurología en el Hospital Barros Luco-Trudeau bajo la tutela del Profesor Oscar M arín. En 1978 hizo una estadía de perfeccionamiento en el M assachussets General Hospital de Boston, EE.UU. Fue escalando grados académicos hasta que en 1980 alcanzó el grado de Profesor Titular de Neurología de la Pontificia Universidad Católica. Creó el Servicio de Neurología del Hospital Sótero del Río y fue su jefe entre 1971 y 1986. Participó en numerosos proyectos de investigación nacionales e internacionales en las áreas de enfermedades extrapiramidales, enfermedades cerebrovasculares, neuromusculares, epilepsia, y Enfermedad de Alzheimer. $\mathrm{Ha}$ trabajado ya por muchos años en la Comisión de Neurología de la Asociación de Facultades de Medicina de Chile, de la cual fue su presidente. Es miembro activo de la Sociedad de Neurología, Psiquiatría y Neurocirugía de Chile. Court ha recibido innumerables distinciones y premios entre los que se cuentan el premio anual "Sociedad M édica de Santiago" en 1969, por su trabajo "L-Dopa en el Tratamiento del M anganismo crónico". Ha sido distinguido con honores como el mejor docente de la carrera en múltiples oportunidades por sus alumnos. El Servicio de Salud M etropolitano Sur Oriente lo ha premiado también por su contribución asistencial en el Hospital Dr. Sótero del Río. La Sociedad de Neurología, Psiquiatría y Neurocirugía de Chile lo nombró M aestro de la Neurología Chilena en 1994 y en 1998 miembro honorario.

A comienzos de los años 70, Court crea la primera cátedra de Neurología en la Facultad de M edicina de la Universidad Católica de Chile. Inicialmente, las actividades docentes y asistenciales se desarrollaron en el H ospital Dr. Sótero del Río, agregándose en los años 80 el Hospital Clínico de la Universidad Católica y el Centro de Diagnóstico de San Joaquín. El grupo de trabajo que lideró aumento desde dos en un comienzo, hasta más de 15 en la actualidad, la mayor parte con formación de subespecialidad completa en centros extranjeros de alto nivel. Jaime Court ha impartido la enseñanza de la especialidad a nivel de pregrado y postgrado y formado varias decenas de especialistas nacionales e internacionales.

Todos quienes hemos tenido el privilegio de compartir estrechamente con Jaime Court sentimos que nos dio mucho y con generosidad y nosotros aprendimos lo que quisimos o pudimos. En una reciente conversación con sus alumnos de postgrado, se mencionaron tantas cualidades de este profesor que sería muy largo de detallar. Se lo reconoce como conciliador, prudente, valorador de las personas indistintamente, siempre disponible para lo técnico y lo humano, erudito, solidario y respetuoso con el paciente y el alumno, comprometido, serio, estricto, amable, muy generoso. Se esmera en entregar todo lo que sabe y es el primero en investigar lo que no se conoce. Producto de su estudio y reflexión permanente, tiene mucho conocimiento, pero más aún sabiduría. Es hábil en el diagnóstico, riguroso en sus planteamientos y siempre veraz. No se queda con la palabra aunque la suya sea la mejor, sino que hace participar a toda su gente y respeta sus opiniones. Es comprensivo y consecuente, pero por sobre todo leal.

Sus clases y presentaciones clínicas fascinan a la audiencia, tal como lo hacía en el siglo XIX Jean Martín Charcot, el padre de la neurología moderna. Sus clases eran y son sencillamente espectaculares, apasionantes y como dijo Joseph Pulitzer, el fundador de los premios que llevan su nombre y le gustaba recordar a Court, cada una fue... "breve para que se escuche, clara para que se entienda, veraz para que se crea y entretenida para que se recuerde". Dichas clases constituyeron sin duda un poderoso estímulo para que muchos de sus alumnos se sintieran de inmediato atraídos por la neurología. De su docencia nos ilustra una de sus más destacadas discípulas, la Dra. María Cristina M iranda... "Tiene un modo muy particular de enseñar, haciendo las cosas más complicadas de una simpleza extraordinaria". Otro de sus discípulos, el Dr. Jaime Godoy, apunta... "Entrega su conocimiento de un modo siem- 
pre sencillo, como un fruto maduro, procesado por la reflexión, seguro de que hará crecer a quien lo escucha. Este M aestro nuestro, no utiliza adornos para enseñar. Ha podido hacer clases por décadas sin recurrir al uso de diapositivas, y el secreto de este éxito es simplemente que se entrega a sí mismo en la docencia". Hace honor al Decálogo del Maestro de la M istral cuando dice a los profesores: "vivifica tu clase. Cada lección ha de ser viva como un ser" y agrega "saber enseñar es simplificar sin restar esencia". Un verdadero maestro, dice la poetisa, "explica lo que sabe y enseña lo que es". Porqué admiramos tanto a este profesor?... porque al enseñarnos como es, nos ha dejado extasiados.

Al referirse a Jaime Court, su discípulo Godoy agrega: "Ciertamente no he visto jamás a alguien que trate con más genuina delicadeza y abnegación a un alumno. Qué lejana su forma de ser de la actitud profesoral, de superioridad, que muchas veces busca brillar y deslumbrar antes que nada. Esta delicadeza, rasgo tan distintivo y obvio de su modo de ser docente, es siempre su primera enseñanza, que no pasa desapercibida ni para el educando ni para sus pares docentes que presenciamos este proceso. No tengo dudas de que ha sido ésta la experiencia de todos los que hemos sido sus alumnos. Esta sorprendente, cautivante y hoy día desgraciadamente inusual forma de enseñar, genera necesariamente una inmediata admiración y adhesión y desencadena el primer y más importante elemento de la docencia: la motivación. Un alumno que se siente acogido, nada menos que por un admirado profesor, que jamás le es mezquino con su tiempo, que le hace ver sutil o expresamente que la duda planteada es importante o que el modo en que el alumno aborda un determinado problema, es interesante 0 inteligente, no puede sino sentirse estimulado a aprender. Jamás lo hemos escuchado escandalizarse por una pregunta que contenga un error conceptual importante, incluso hecha por quien ya debería estar al tanto, menos todavía reprochar el error al alumno. Pero lo hemos visto corregir, siempre a su modo, siempre enseñando, siempre con esa bondad que le es tan natural, siempre dejando claro que tiene ante sí una persona. Son conocidos sus malabares para demostrar que aun una respuesta manifiesta, insólitamente errónea tiene algo de verdad, algo que explica porqué no es tan disparatada, para alivio del interrogado quien ya vio hundirse en sus asientos a más de uno y ya escuchó más de una carraspera de reprobación". En otro comentario Godoy agrega: "Es fácil imaginar que todas estas virtudes aparecen también en la relación con sus pacientes. Su modo sencillo, acogedor y extremadamente respetuoso es fácil de apreciar en sus visitas por los pisos. Es el primero y muchas veces el único siempre preocupado de no inquietar al enfermo con comentarios técnicos inoportunos o simplemente malinterpretables, siempre pendiente de entregar alguna luz de esperanza al enfermo o entorno familiar devastado por un pronóstico de la peor especie, incluso con una perdonable mentira piadosa. Justificadamente, la admiración que los pacientes tienen por su persona no es menor que la mostrada por sus alumnos".

Court, no sabemos cómo, siempre lideró entre nosotros la adaptación al cambio hoy vertiginoso, y nos ayudó a asumirlo. Jamás le notamos angustia por el conocimiento nuevo... quizás porque iba antes que aquel. Nunca se enorgulleció ni hizo gala de su dominio de lo nuevo. Su modestia no lo permitía. Nuevamente, siempre nos simplificó lo difícil, nos ayudó a disfrutar con lo nuevo, a esperarlo con entusiasmo, a estar preparados para modificar de repente lo aprendido y usado por tantos años.

Son muchos los alumnos que atraídos por el ser de este hombre tan grande, abrazaron la N eurología como su especialidad. Y fueron casi siempre los mejores alumnos de medicina los que quisieron ser neurólogos. Muchos tuvieron que esperar un año o más para obtener un cupo en su programa de formación. Hoy están felices de haberlo hecho. Así, Court ha dejado una huella muy profunda en la medicina nacional.

Court ha escrito mucho... y siempre para los demás, dejando a firme su experiencia y reflexión privilegiada. Sus trabajos superan el ciento, sin 
considerar los numerosos capítulos en libros, apuntes de clases y seminarios y artículos de divulgación que nos ha dejado.

En 1972 Jaime Court crea los "Cuadernos de Neurología", publicación que en su género es la más antigua de habla hispana y que ha aparecido de manera ininterrumpida todos los años. Se han publicado en ellos más de 313 artículos y han participado muchísimos autores. Court ha publicado hasta ahora 33 trabajos en ellos. Como ha sido su costumbre, en muchos de ellos ha invitado a sus alumnos, lo que naturalmente es expresión de su preocupación por la docencia. Estos "cuadernos" han sido para muchos, literatura cada año esperada y también obligada y se ha constituido también en un buen comienzo para que los alumnos de post grado se introduzcan en la literatura científica, estimulándolos a complementar con la escritura, el ejercicio profesional.

Como se ve Jaime Court ha sido sobre todo un gran docente, su producción de neurólogos ha sido excepcionalmente abundante en cantidad y también en calidad. A pesar de contar con un número creciente de discípulos que le apoyan, ha llevado siempre el mayor peso de la docencia. Goza enormemente al ver que sus alumnos de pre y postgrado han aprendido lo que les enseña y como usan esos conocimientos en la práctica: se alegra con sus logros y se entristece con sus fracasos. Quiere mucho a sus alumnos quienes al percibirlo así, pueden desarrollar al máximo sus potencialidades. En privado, me ha confiado que admira a sus alumnos por su esfuerzo y los siente como hijos adoptivos. Quizás esto contribuya a que haya logrado desarrollar tanto algunas de sus virtudes docentes.

En la vida universitaria, pocas personas han llegado a ser tan queridas como Jaime. En realidad, Court se ha entregado a si mismo usando como pretexto la enseñanza de una disciplina. Nuestra Mistral, a quien nuestro profesor tanto admira, parece haberle dicho.... "piensa que Dios te ha puesto a crear el mundo".

Jaime Court M aestro de la Neurología, retirado sigue enseñando. Permanece presente a nuestro lado cada día, acompañándonos frente a cada paciente que veamos, a cada clase que hagamos, a cada estudio o trabajo que escribamos. Cuán agradecidos hemos quedado. Tenía razón H ipócrates cuando se refería a la enorme deuda con que quedan los discípulos para con sus maestros.... Court ha sido un ejemplo de entrega como profesional y docente, pero sobretodo como ser humano, y del modo más característico de él: genuinamente sin esperar reconocimiento alguno. 